\title{
ALONG THE BORDER: AN AGENT-BASED MODEL OF MIGRATION ALONG THE UNITED STATES- MEXICO BORDER
}

\author{
Amira Al-Khulaidy \\ Melanie Swartz \\ Department of Computational and Data Sciences \\ George Mason University \\ 4400 University Drive \\ Fairfax, VA, USA \\ aalkhula@gmu.edu
}

\begin{abstract}
Migration to the United States (U.S.) has been an ongoing topic in the political discourse. In the specific case of migration using the United States-Mexico border, it is difficult to understand the patterns and uncertainty that comes from trying to capture the behavior of individuals and groups. Migrants using the U.S.Mexico border present features and migration patterns that are unique, particularly in the case of group migrations, structured social networks, and caravans that travel towards the border together. We build an agent-based model (ABM) that simulates migrant decision-making of which border to choose, to test the effects of social influence on an agent's migration strategy, as well as the effects of policy changes on migrant behavior. Deciphering these emerging patterns of migration and social phenomena can help provide researchers and policymakers with an added dimension of knowledge on how to better utilize resources at the U.S. ports of entry.
\end{abstract}

Keywords: agent-based modeling, migration, human behavior, social influence, U.S.-Mexico border.

\section{INTRODUCTION}

Several disciplines have attempted to understand migration through various lenses, taking into account economic factors, political and social conflict, as well as war and natural disasters to explain why people migrate (Suleimenova et al. 2017). There are also different theories of why and how humans migrate that have been expanded over the centuries (Ravenstein 1885; Stouffer 1940; Hoerder 2002; Manning 2005). Migration is a complicated form of spatial mobility with push and pull factors that can vary greatly among individuals, and also with different types of migration patterns that can be seen over history (Lee 1966). In the specific case of migrants utilizing the U.S.-Mexico border (southwestern border) to cross into the United States, the push factors which include food insecurity and violence, and pull factors such as jobs, family connections, and the idea of a better life have stayed the same. However, these reasons do not explain the new patterns of migration via caravans which has seen an increase as of 2018 (Correa-Cabrera 2019).

Data from the United States Customs and Border Patrol (CBP) for the past ten years spanning 2008-2018 show that the total apprehensions at the southwestern border was over four million for the nine southwestern sectors. The northern and coastal border sectors for the same period of time only totaled 51,315 and 59,482, respectively (CBP 2018). During the same time period, the CBP reports that while data on the number of bodies discovered near the southwestern border with no known cause of death is incomplete, an estimated 3558 people may have died due to migratory attempts. 
The U.S.- Mexico border, which is 3,145km in length, with 48 border crossings, and 330 active ports of entry (Homeland Infrastructure Foundation-Level Data, 2019), has historically been patrolled off and on since 1904, with various concerns over the past century ranging from immigration to smuggling during Prohibition, as well as drug smuggling and human trafficking more recently (CBP 2018). In the specific case of migrants at the southwestern border, the trajectory and final destinations, as well as the several attempts to cross the border, are also a topic of interest because many people will make several stops along the way, and also migrate to more than one place (Doris 2019) before entering the U.S., or in some cases enter, leave and re-enter several times over the years. Other studies have looked at migrant willingness to travel, resource availability, as well as risk aversion (Huber and Nowotny 2018; Bah and Batista 2019). It is difficult to obtain data from individuals who can describe firsthand their reasons and choices for migrating. However, the Mexico Migration Project (MMP) has been collecting various types of individual and household data since 1982. The firsthand accounts and narratives of why migrants choose to leave, as well as the survey data regarding socio-economic status, reveals some consistent responses in terms of motivations for migrating.

Over the decades, the scope and budget for patrolling the U.S. border increased with new political goals and new leadership (CFR 2018; Meyer and Isacson 2019). Agent-based models can help contextualize and visualize these patterns, as well as provide new insights. In trying to understand large complex systems such as migration, simulations can provide a virtual experimental space that can help educate, and provide decision support (Hawe et al. 2012), while also providing a better understanding of dynamic and emergent behavior. This paper aims to use an agent-based model to understand the group behavior of migrants along the U.S.-Mexico border. The background (section 2) goes over the context for this study. The model (section 3) includes two major components: a) the agents (migrant-agent) and how they make decisions, and b) the environment and parameter testing. Section 4 goes over the results of the model runs and the validation against CBP data. Section 5 provides conclusions and some ideas for areas of further work.

\section{BACKGOUND}

Migration has been of interest across multiple disciplines, and migration modeling has traditionally been done using gravity, stocks and flows, as well as spatial interaction models (Klabunde et al. 2016). Some computational models, including agent-based models, have attempted to determine where people migrate, as well as the routes they take and the refugee camps they may end up in. An example is the FLEE model (Suleimenova et al. 2017). Other models that track changing geography due to political unrest, such as GeoSim (Cederman and Girardin 2007), also touch on the patterns of migration. Informational models, such as the GIS maps created by the United States Department of Transportation (U.S.DOT, 2018), record the numbers of people who come through ports, roads, and other transportation routes. Agencies such as the World Bank collect data on human movement across country lines (Suleimenova et al. 2017). These informational and forecasting models support a greater understanding of migration and help develop methods for dealing with the ongoing complexities of migration (Haas 2010; Angelucci 2012; Carriquiry and Majmundar 2013; Lin et al. 2017). However, because migration is a process that occurs on the individual level with "bottom-up" effects (Epstein and Axtell 1996), agent-based models better capture the complex processes and decision-making processes of migrants (Ajzen 2011; Klabunde et al. 2013; Hebert 2018; DeAngelis et al. 2019). The goal of this paper is to contribute to the existing literature on migration, with an added emphasis on the behavioral patterns of migrants, and to test migration policy scenarios, specifically for migrants who utilize the U.S.-Mexico border.

Migration patterns and the composition of people attempting to enter the United States through the U.S.Mexico border have characteristics that meet the "refugee" definition established by the United Nations Higher Commissioner for Refugees (UNHCR 2017). The UNHCR uses the 1951 Refugee Convention to define refugee as a "person fleeing conflict or persecution." However, the description of refugee provided by the UNHCR does not capture the entire picture of the people who migrate to the U.S. via the U.S.Mexico Border, and neither does the term "migrant worker," since many migrants are looking to move and establish roots in the U.S. (Massey and Espinosa 1997). In attempting to understand who the migrants crossing the U.S. Mexico border are, it is important to note that they are not uniquely from Mexico. The 
World Bank (2018) lists El Salvador, Honduras and Guatemala as the top origin countries with migrants using the southwestern border as the main point of entry. This can add another layer of challenges in understanding this trend in migration, given that migrants from each country are facing unique push factors (Correa-Cabrera 2014).

With the large number of migrants leaving their countries of origin and ending up in a transitional state along the way without a permanent location, situational dimension and "stop sites" (Crooks and Hailegiorgis 2013; Curry et al. 2018) become the holding place for thousands of people, and attempting to obtain data can become challenging (MPP 2018). Understanding the composition of the migrant population can become more difficult as well. In the case of the U.S.-Mexico border migrants, the migrants "en route" leave their initial locations for a transitory state where they do not have jobs, access to education, medical care, or other opportunities (UNHCR 2017).

\section{THE MODEL}

The traditional understanding of human movement and spatial distance is that most people will choose to travel a shorter distance towards a goal (Ravenstein 1885). However, migrants will travel farther if there is a chance for greater opportunity at a farther distance (Stouffer 1940; Stillwell et al. 2016). In the context of the migrants utilizing the U.S. Mexico border, intervening factors such as family and social connections play a part in choosing a route and deciding next steps. (MPP 2018). Our model was informed by firsthand accounts collected by the Mexico Migration Project (MMP), discussed in section 1. The firsthand accounts and narratives of why migrants choose to leave, as well as data regarding socio-economic status, reveals some consistent responses in terms of reasons for migrating. These narrative accounts serve as qualitative data that we have also validated our model against. Based on this data, the trend is that over almost four decades, social connections and systems of belief that migrants have about the U.S. seem to be underlying factors in deciding to migrate (Dahlstrom 2014; Conte et al. 2014; Schenk 2014).

The model looks to test these theories by experimenting with four migration options for choosing a border crossing. The first method looks at migrants randomly choosing a border and heading towards it. The second method has migrants looking at the border nearest to them, accounting for distance motivated migration. The third method includes selecting a border based on being a part of a group or caravan. In the third experiment, migrants can choose to join a group with a similar goal, updating their own final goal or destination, adhering to the general goal of their newly joined group. In the fourth method, we account for the social network that a migrant belongs to, and they choose a border that they know members from their social network had success in crossing. Migrants who choose a border based on the group/caravan option start out with a heading directing them to choose a border, but their heading for which border they go to is updated by them looking around in their radius, and if most other migrant-agents in their neighborhood are closer to a different border, they may update their trajectory to join a group and head to another border, even if it is farther away which lends itself to the notion of norm reinforcement. Centola (2005) explores norm reinforcement and social influence and explains that "if agents' horizons are limited to immediate neighbors, highly unpopular norms can emerge locally and then spread." Social influence can cause people to behave in certain ways that go beyond calculated decision-making, with Centola (2005) using the example of "The Emperor's New Clothes" by Hans Christian Andersen (1837) to illustrate a classic example of this type of behavioral phenomenon. This type of social influence can also explain adoption of new routes of travel, even when the border is farther away. Figure 1 illustrates how agent's decision-making and behavior results in choosing certain borders over others. Another way that social influence can influence a migrant's choice of border is if they know from their social circle that members have had success crossing certain borders (Ryan 2011; Simon 2019) and are able to communicate this to others in their social networks. The effects of social influence in this case also cause a migrant to choose a border that may be farther away. 


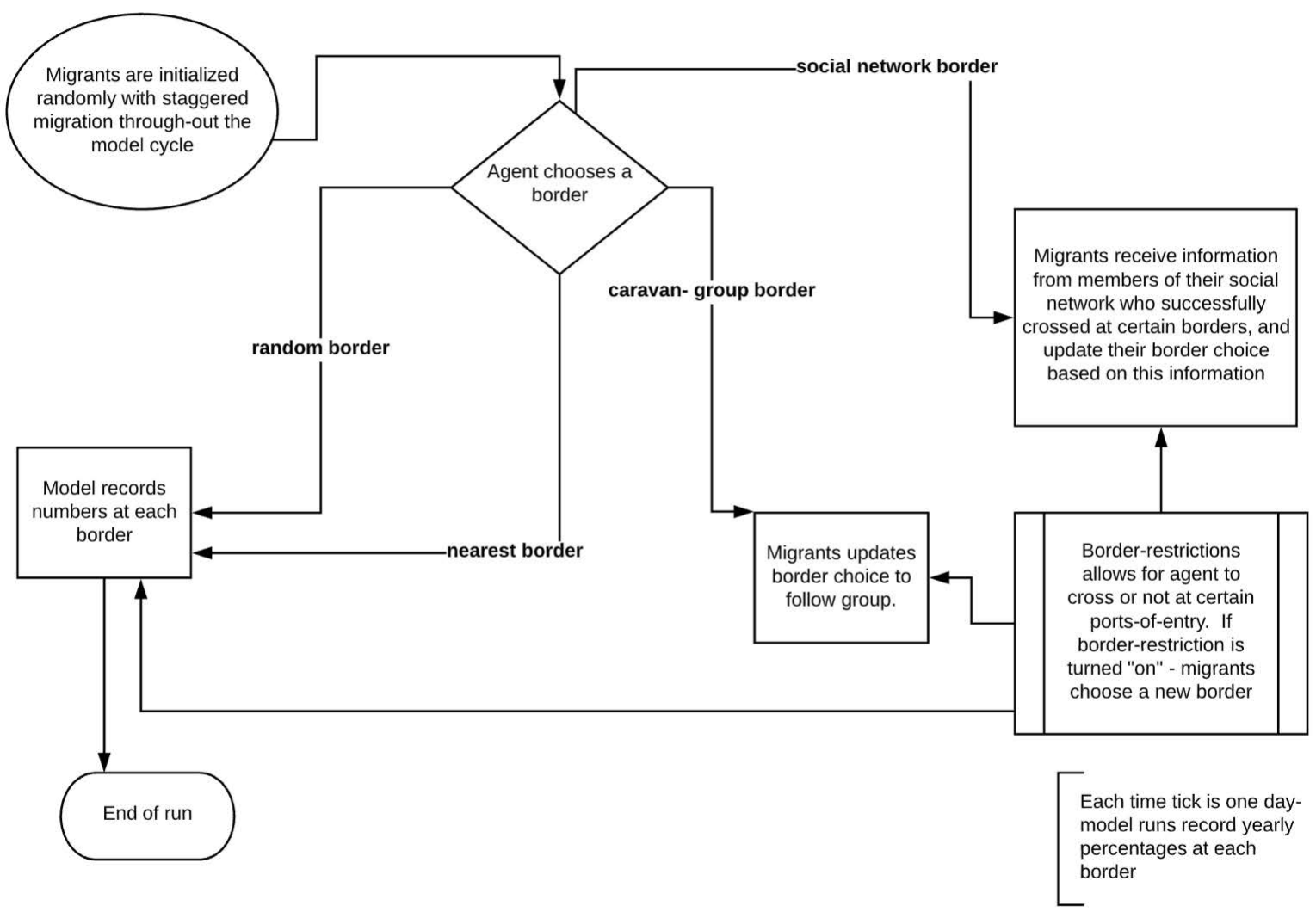

Figure 1: Migrant decision-making and behavior when selecting a border.

\subsection{Agents}

The migrant-agents are initialized with the same set of attributes, migrating at staggered intervals to allow for variability in group behavior. Depending on the type of migrant decision-making for border selection (Gray et al. 2017), migrant-agents can either randomly select a border, choose the closest border, join a group or caravan, or follow the successes of migrants in their network. We tested initialization based on the population of migrant-agents at different districts and found that this approach did not represent the reality of migrant behavior, and random initialization proved to be the most accurate in capturing the flows of migrant behavior toward the southwestern border. Exact average travel speed of migrants is approximately $25 \mathrm{~km} /$ day (Meyer and Isacson, 2019), but the actual number will depend on whether travel is by foot, car, or other modes of transportation, as well as whether migrants are traveling with children, smugglers, or making several stops along the way. Table 1 describes the model components including the agent parameters. 
Table 1: Migrant Variables.

\begin{tabular}{|c|c|c|}
\hline Model Components & Parameters & Description \\
\hline $\begin{array}{l}\text { Model-level parame- } \\
\text { ters }\end{array}$ & $\begin{array}{l}\text { Population-scale: } \\
100,000-\text { random ini- } \\
\text { tialization of agents in } \\
\text { Mexico } \\
\text { border-restriction- "on" } \\
\text { or "off" }\end{array}$ & $\begin{array}{l}\text { Agent initialization is random and staggered at ran- } \\
\text { dom intervals during the model run. Apprehension at } \\
\text { Southwestern border } 476,649 \text { Oct-Dec (CBP, 2015). } \\
\text { Migrants who don't cross at a port of entry and mi- } \\
\text { grants who die en route/not accounted for (Meyer and } \\
\text { Isacson-WOLA 2019). } \\
\text { Random ports that reach capacity and "close" to show } \\
\text { policy effects. This requires agents to turn back and } \\
\text { choose different points of entry based on the migration } \\
\text { strategy the agent is using. }\end{array}$ \\
\hline Environment & $\begin{array}{l}\text { Raster map of U.S.- } \\
\text { Mexico states and bor- } \\
\text { ders. }\end{array}$ & $\begin{array}{l}\text { Grid } 67 \times 43 \text { with each patch representing } 25 \mathrm{~km} \text {. Map } \\
\text { placement on cellular-grid-border is } 3,145 \mathrm{~km} \text { in } \\
\text { length and scaled proportionally. }\end{array}$ \\
\hline $\begin{array}{l}\text { Agent attributes and } \\
\text { behaviors }\end{array}$ & $\begin{array}{l}\text { 1-willingness-to-mi- } \\
\text { grate } \\
\text { 2-risk-aversion } \\
\text { 3-average-means } \\
\text { 4- border-choice: } \\
\text { a) border-random b) } \\
\text { border-nearest c) bor- } \\
\text { der-caravan d) border- } \\
\text { network-hometown }\end{array}$ & $\begin{array}{l}\text { 1-Parameter to capture various push and pull factors } \\
\text { (Bah and Batista 2019). } \\
\text { 2- Scale to account for risk aversion can be increased } \\
\text { to show the effects of socio-economic or political up- } \\
\text { heaval. Agents may take more risks if conditions are } \\
\text { favorable for migration (Huber and Nowotny 2018). } \\
\text { 3- Attributes based on reported migrant experiences, } \\
\text { as well as census data. If agents have more resources, } \\
\text { that may provide more incentives to migrate (Bah and } \\
\text { Batista 2019). } \\
\text { 4- Agents can choose their border: a) randomly, b) } \\
\text { based on nearest border, c) based on group influ- } \\
\text { ence/caravan, or c) based on information from their } \\
\text { social network of those in their hometown who have } \\
\text { crossed at a border successfully (Simon } 2019 \text {; Centola } \\
\text { 2015, Dekker et al. 2014; Simon 1991). }\end{array}$ \\
\hline
\end{tabular}

Representing decision-making in agent-based models can provide a challenge, particularly when attempting to endow simulated people with human cognitive capacities (Simon 1991; Meyfroidt 2013; Mcglade 2014; Tesfatsion 2003). In models that look at animal migration, such as the "flocking model" (Wilensky 1997, Reynolds 1993), the behavior is understood from patterns that emerge. These patterns show how individual actions create larger effects when observed as a holistic entity made up of individual, heterogeneous actors. Simulations can abstract, reproduce and follow these patterns for greater understanding (Crooks et al. 2019; Grimm et al. 2005). This is also the case with crowd models, that look at human behavior and focus on the spatial patterns of the behavior of individuals (Batty 2003). Some models have combined both human behavior with a focus on flocking to understand these patterns (Luo et al. 2008; Belz et al. 2013; Deshmukh 2018). The models conclude that spatial patterns can provide an accurate spatial and visual representation of the micro-behavior of people in some scenarios, but understanding motivations and decision-making is more challenging. Having first-hand qualitative data helps with the robustness of the model, and despite the challenges of collecting qualitative data in this case, the MPP (2018) narrative data we refer to, along with the yearly totals collected by the CBP (2018) help provide a more holistic picture of what we are attempting to model. Abstraction in modeling is essential to gain insight (Gilbert and Troitzsch 2005) and 
replicating the observed flow of migration in this case better illustrates the behavior observed in the real world. This model has an underlying assumption that part of the motivation of the individuals and how they affect, and are affected by, relationships with others on the same journey (Price and Allen 1990; Thoni et al. 2015), has to do with communication via social media, news, and other social interactions (Fulk et al. 1987; Slater 2007), as well as more sophisticated forms of social influence that can help explain some of these behaviors (Moussaid, et al. 2013; Centola 2010).

Migrant-agents are heterogeneous and make a decision at each model interaction to update their chosen border that may be different than that of a fellow agent. However, the macro-structure of the movement that results from the group behavior of these migrant-agent does provide behavior that is quantitatively and qualitatively consistent with the data we observe from the real world. In complex adaptive systems, we do not know what micro-behaviors are causing the patterns we observe. Therefore, if an observation can lead one to determine that the patterns "look" like something we observe (Miller and Page 2007), then a computational algorithm that captures this pattern may enhance our understanding of the social science phenomena.

\subsection{Environment and Parameter Testing}

Migrant-agents are initialized on a stylized map of Mexico that provides enough information and averages that reflect data collected by the CBP (2018) and serves as a tool for validating our model. The migrantagents in the model are generated to follow the logic based on the parameters of the models ( Figure 1, and Tables 1 and 2, respectively). CBP and DOT data summarize migrant crossings, apprehensions, and deaths along the nine border sectors. The model map also shows the approximate location of the nine main ports of entry (Table 2).

The model captures this by setting a border line as the most immediate measurable point of success. The model takes place on a raster landscape that theoretically captures movement from the south to the north, and does not account for a more granular landscape. The grid represents the different cities on both sides of the U.S.- Mexico border (Table 2), and the landscape patches are also scaled to meet the distance and time it takes migrants to reach a border point.

Table 2: Environmental Components.

\begin{tabular}{|l|l|}
\hline Type & Description \\
\hline Landscape & Land (including borders), water \\
\hline Countries & $\begin{array}{l}\text { United States, Mexico, El Salvador, Honduras, Guate- } \\
\text { mala, and Belize }\end{array}$ \\
\hline Mexico districts & District name, 2015 census population estimates \\
\hline International border & Southwestern border (U.S.- Mexico border) \\
\hline Border sectors (ports of entry) & $\begin{array}{l}\text { Big Bend (BB), Del Rio (DR), El Centro (EC), El Paso } \\
\text { (EP), Laredo (LR), Rio Grande Valley (RG), San Diego } \\
\text { (SD), Tucson (TS), Yuma (YM) }\end{array}$ \\
\hline
\end{tabular}

Data on the origin of each migrant is not something that can be captured in an accurate or meaningful way, nor would we have access to data on migrants that use non-traditional routes and enter the country undetected. Agents in this model do not follow precisely along the location of roads for the purposes of keeping the model relevant (Gilbert and Troitzsch 2005). The averages from the CBP are captured in the model due to their simplicity and ease of validation, and time in this model advances by a day in order to allow for short-term individual decisions that create weekly, monthly, and yearly effects, which is then used to validate against the existing data which is measured monthly and yearly (CBP 2018). 
To verify the model behavior, we conducted parameter sweeps. We found that initial population numbers had less of an effect on the model runs, outside of allowing for more numbers at each border, but the percentages did not show any difference. Each parameter combination was run 30 times on average, and each run was observed for a minimum of one year (365 days). Additional testing was conducted with border-restriction turned "on" and "off." When border restriction was "on," random ports of entry reached a maximum capacity and turned migrants away, requiring the migrant-agents to choose different ports of entry- this reflects policy changes or lack of resources at certain ports of entry. Due to the geography of the states of the U.S. and Mexico, the model considers surrounding bodies of water, which is represented in the model. In this model migrant-agents navigate the geography of the landscape, including travel by water.

\section{RESULTS AND VALIDATION}

The model results show an average across all runs, where model outputs for each sector were recorded and averaged. This provides a baseline for comparing the model averages with averages from CBP data, shown in Figure 2. The comparison shows the percentages for each type of migration strategy and border choice of the model with data gathered by the CBP.

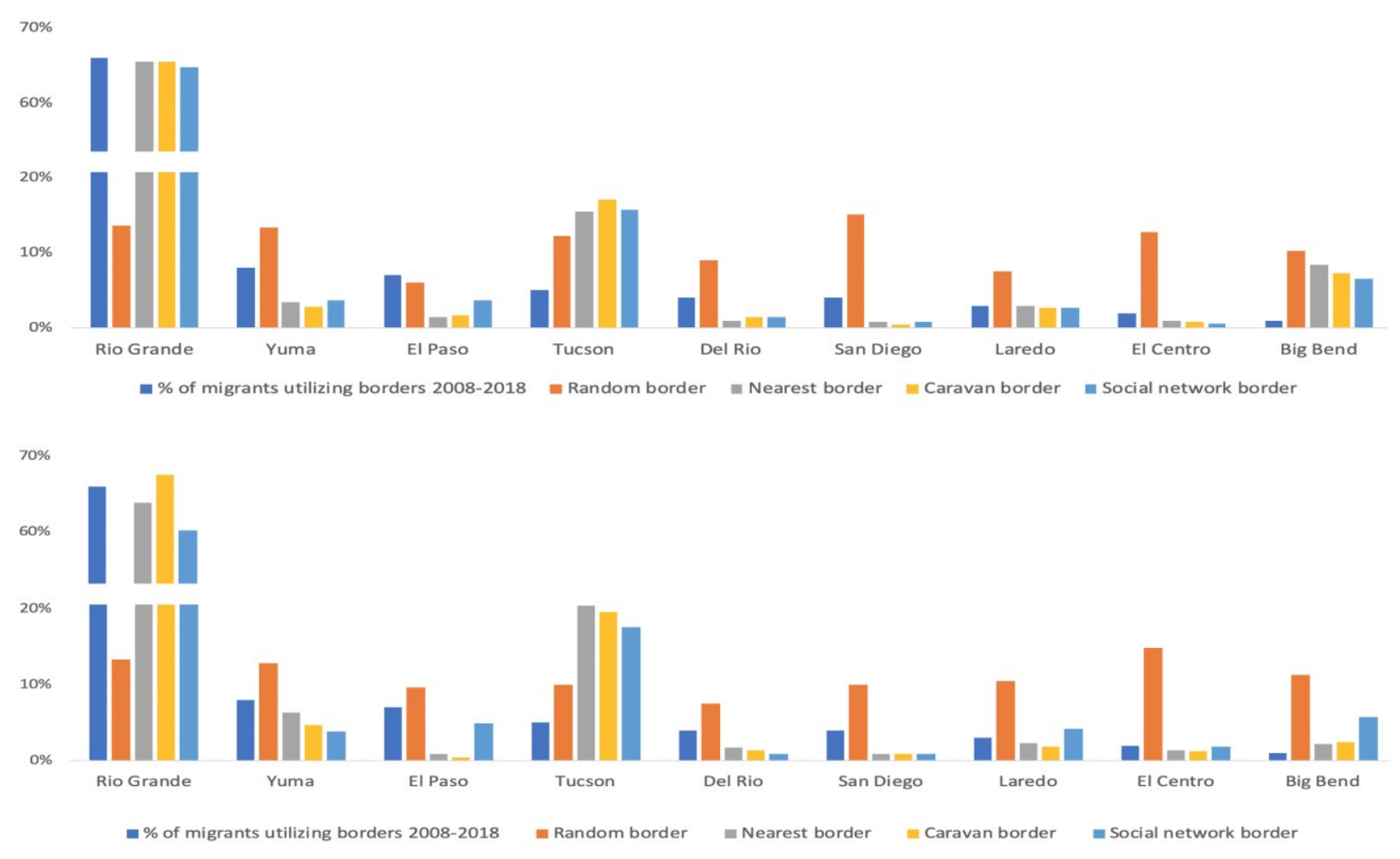

Figure 2: Percentages of preferred ports of entry from CBP (2018) data compared to output from the parameter sweeps of the model with border-restriction "off" (top), and parameter sweeps of the model with border-restriction "on" (bottom).

The importance of comparing different migration strategies can help understand the patterns that we see in the case of migrants using the southwestern border. Border-restriction has an effect on the social modes of choosing a border, the caravan and social network strategies show that policy changes and updates represented by border-restrictions is communicated to other agents and affects their decision on which border is chosen. The model results demonstrate this and show that migration is not random, and distance is not the only factor determining why migrant-agents choose a port of entry, especially when policies or changes are 
implemented and people rely on other people for information which may affect their choice of route and port of entry. The policy test in the model was to have border restriction turned "on" or "off". When the border-restriction was turned "on," borders reached capacity at a certain threshold and did not allow more migrants to enter. Migrants in the model then needed to choose a different port of entry. In the restricted border scenario, the social network driven strategy, which relied on agents communicating with other migrants produced similar patterns to the data from the CBP after new policies were implemented in 2019 (CBP 2019). What this demonstrates is that with new policy changes, the influence of the social network is important and needs to be accounted for when modeling agents who adapt to changing information in their environment (Centola 2005; Gray, et al. 2017; Correa-Cabrera 2019; Migration Policy Institute 2019). While the parameters and decision-making choices for this model have provided results that match the patterns of the real-world data as well as the narrative accounts of migrants collected by the MMP, further verification and calibration with additional data may be needed to conclude that the factors chosen are only reason for the observed model and agent behavior. However, the results we obtain in the model do provide reason to believe that social influence and group behavior may have an impact on migrant decision-making, particularly in times of uncertainty, or policy changes which we represent by having border-restriction turned "on". These results can contribute to existing research and provide a greater understanding of the observed patterns seen in migrants using the U.S.-Mexico border.

The individual yearly data showed little variation in terms of percentages of migrants apprehended, with the exception of Big Bend, which had the greatest rate of change from one year to the next. This is important to note, because in several runs, Big Bend shows the greatest deviance from the expected results. As of March 2019, reports show that large groups of migrants have been apprehended at Big Bend, which represents over a 20\% increase in the first four months of 2019 (Gonzalez-Barrera et al. 2019, CBP 2019, and DHS, 2019). This is interesting to note because future data may provide better validation for this model, given the timely example of Big Bend and other ports that in the model produce larger numbers when border restriction is "on."

\section{CONCLUSION AND AREAS OF FURTHER WORK}

The model tests migration strategies that can help inform our understanding of which ports and sectors may receive a large number of migrants and may require additional resources. We also attempt to capture the drivers of the decision-making processes and social influences that propel the trajectory of migrants towards the ports of entry. Based on the model results, social influences and collective behavior may account for some of the patterns observed in migrants using caravans or traveling in groups. Agent-based models may be the only type of modeling at this time that can account for a dynamic understanding of the social phenomenon of migration, especially when trying to understand and experiment with the effects of policy change on human behavior. Further studies could demonstrate whether these behaviors hold true in different migration scenarios with similar push and pull factors.

Additional data on rate of change for each of the sectors is also available, and provides additional criteria for validation; however, the data is incomplete and captures only a portion of the people who migrate and are apprehended, and not those that enter successfully. Capturing how humans make decisions when migrating can shed light and propel further work that can be expanded to compare different case studies. The policy implications of understanding what ports of entry may see a spike in migrants if one port of entry is closed, or if a new policy is implemented, can help policymakers with managing resources. With modeling migrant decision-making, we can gain insight into some of the uncertainties associated with long-term planning for complex issues such as human migration, especially when migrants are uncertain of new policy changes and rely on their social connections for information.

There is more work to be done in understanding human decision-making, particularly with migration. ABMs are a helpful tool for understanding the complex migratory patterns and behaviors of people, and this model illustrates how we can better capture some aspects of this complex phenomenon.

The full description of the model and source code is provided in the authors' GitHub page, linked below in the author biography section. 


\section{REFERENCES}

Ajzen, I. 2011. "The theory of planned behavior: Reactions and reflections". Psychology \& Health. 26(9). 1113-1127. https://doi.org/10.1080/08870446.2011.613995

Carriquiry, A \& Majmundar, M. 2013."Migration-Relevant Surveys in the United States and Mexico: Background".Retrieved from http://www.nap.edu/openbook.php?record_id=13498\&page=39

Angelucci, M. 2012. "US Border Enforcement and the Net Flow of Mexican Illegal Migration. Economic Development and Cultural Change. 60 (2). 311-357. https://doi.org/10.1086/662575

Attari, S., Krantz, D., \& Weber, E. 2014. "Reasons for cooperation and defection in real-world social Dilemmas". https://doi.org/10.1037/e573552014-014

Batty, M. 2001. “Agent-Based Pedestrian Modeling. Environment and Planning B”. Planning and Design. 28(3). 321-326. https://doi.org/10.1068/b2803ed

Bah, T. L., \& Batista, C. 2019. "Understanding Willingness to Migrate Illegally: Evidence from a Lab in the Field Experiment."

Belz, M., Pyritz, L. W., \& Boos, M. 2013. "Spontaneous flocking in human groups". Behavioral Processes. 92. 6-14. https://doi.org/10.1016/j.beproc.2012.09.004

Centola, D. 2010. "The Spread of Behavior in an Online Social Network Experiment." Science, 329(5996). 1194. https://doi.org/10.1126/science. 1185231

Centola, D., Willer, R., \& Macy, M. 2005. “The Emperor's Dilemma: A Computational Model of SelfEnforcing Norms". American Journal of Sociology. 110(4).1009-1040. https://doi.org/10.1086/427321

Conte, R., \& Paolucci, M. (2014). “On agent-based modeling and computational social science”. Frontiers in Psychology. 5. https://doi.org/10.3389/fpsyg.2014.00668

Correa-Cabrera, G. 2014. "Violence on the "Forgotten" Border: Mexico's Drug War, the State, and the Paramilitarization of Organized Crime in Tamaulipas in a "New Democratic Era"." Journal of Borderlands Studies. 29(4). 419-433. https://doi.org/10.1080/08865655.2014.982888

Correa-Cabrera, G., \& Bersin, A. 2018. "Migrant activists and human smugglers collaborated at the Southern border: Innocents lost.". The Hill.

Correa-Cabrera, G., \& Bersin, A. 2019. "Paradojas: Activismo y uso político de caravanas." SimEmbargo. Retrieved from https://www.sinembargo.mx/16-01-2019/3523007

Correa-Cabrera, G., \& Staudt, K. 2014. "An Introduction to the Multiple US-Mexico Borders". Journal of Borderlands Studies. 29(4). 385-390. https://doi.org/10.1080/08865655.2014.982473

Crooks, A., Malleson, N., Manely, E., \& Happenstall, A. 2019. Agent-Based Modelling \& Geographical Information Systems: A Practical Primer. Sage.

Crooks, A., \& Hailegiorgis, A. 2013. "Disease Modeling Within Refugee Camps: A Multi-agent Systems Approach". Proceedings of the 2013 Winter Simulation Conference.

Customs and Border Patrol (CBP). 2019. Southwest Border Migration FY 2019.

Dahlstrom, M. F. 2014. "Using narratives and storytelling to communicate science with nonexpert Audi ences". Proceedings of the National Academy of Sciences.111(Supplement 4). 13614 13620.https://doi.org/10.1073/pnas.1320645111.

DeAngelis, D. L., \& Diaz, S. G. 2019. "Decision-Making in Agent-Based Modeling: A Current Review and Future Prospectus". Frontiers in Ecology and Evolution.6. https://doi.org/10.3389/fevo.2018.00237.

Dekker, R., \& Engbersen, G. 2014. "How social media transform migrant networks and facilitate Migration”. Global Networks. 14(4). 401-418. https://doi.org/10.1111/glob.12040.

Department of Homeland Security. 2019. U.S. Border Patrol Southwest Border Apprehensions by Sector Fiscal Year 2019. DHS.

Deshmukh, V. 2018. "Modeling Human Migration Dynamics in Netlogo”. Master of Science, San Jose 
State University. https://doi.org/10.31979/etd.6q34-pckc

Doris, M. 2019. "Policy Solutions to Address Crisis at Border Exist, But Require Will and Staying Power to Execute". Migration Policy Institute. Retrieved from https://www.migrationpolicy.org/news/policysolutions-address-crisis-border-exist-require-will-staying-power

Durand, J., \& Massey, D. S. (Eds.). 2006. "Crossing the border: research from the Mexican migration Project”. Presented as papers at a binational conference held in Puerto Vallarta, Mexico, on March 15 and 16, 2002 (1. pbk. ed). New York. Russell Sage Foundation.

Epstein, J., \& Axtell, R. 1996. Growing Artificial Societies: Science From The Bottom Up. Brookings Institution Press.

Fulk, J., Steinfield, C. W., Schmitz, J., \& Power, J. G. 1987. “A Social Information Processing Model of Media Use in Organizations". Communication Research. 14(5). 529-552. https://doi.org/10.1177/009365087014005005.

Gilbert, G. N., Troitzsch, K. 2005. Simulation for the Social Scientist. (2nd ed.). Maidenhead. Open University Press.

Gonzalez-Barrera, A. and Manuel Krogstad, J. 2018. "What We Know About Illegal Immigration from Mexico". Pew Research Center. www.pewresearch.org/fact- tank/2018/12/03/what-we-know-about-illegalimmigration- from-mexico/.

Gray, J., Hilton, J., \& Bijak, J. 2017. "Choosing the choice: Reflections on modelling decisions and behaviour in demographic agent-based models". Population Studies. 71(sup1). 85-97. https://doi.org/10.1080/00324728.2017.1350280

Grimm, V., Revilla, E., Berger, U., Jeltsch, F., Mooij, W., Railsback, S., Thulke, H, Weiner, J, Wieganm T, Deangelis, D. 2005. "Pattern-oriented modeling of agent-based complex systems: Lessons from ecology". Science. 310(5750). 987-991. https://doi.org/10.1126/science.1116681.

Haas, H. de. 2010. "The Internal Dynamics of Migration Processes: A Theoretical Inquiry”. Journal of Ethnic and Migration Studies. 36(10). 1587-1617. https://doi.org/10.1080/1369183X.2010.489361.

Hawe, G. 2019. "Agent-based simulation for large-scale emergency response: A survey of usage and Implementation”. Semantic Scholar. Retrieved May 9, 2019.

Hébert, G. A., Perez, L., \& Harati, S. 2018. “An Agent-Based Model to Identify Migration Pathways of Refugees: The Case of Syria". Agent-Based Models and Complexity Science in the Age of Geospatial Big Data. (pp. 45-58). https://doi.org/10.1007/978-3-319-65993-0_4.

Hoerder, D. 2002. Cultures in Contact. World Migrations in the Second Millennium. Duke University Press.

Huber, P., \& Nowotny, K. 2018. "Risk Aversion and the Willingness to Migrate in 30 Countries”. [Working Paper].

INEGI. Instituto Nacional de Estadistica y Geografia. 2018 . Encuesta Nacional de la Dinámica Demográfica (ENADIDINEGI. https://www.inegi.org.mx/programas/enadid/2018/.

Klabunde, A., \& Willekens, F. 2016. "Decision-Making in Agent-Based Models of Migration: State of the Art and Challenges”. European Journal of Population. Revue Européenne de Démographie. 32(1). 7397. https://doi.org/10.1007/s10680-015-9362-0.

Cederman, Lars Erik \& Girardin, Luc. (2007). "Toward realistic computational models of civil Wars". Presented at the Annual Meeting of the American Political Science Association. Chicago. Retrieved from https://icr.ethz.ch/publications/cederman2007towards.pdf.

Lee, E. 1966. “A Theory of Migration”. Demography. 3(1), 47-57.

Lin, L., Carley, K. M., \& Cheng, S.-F. 2016. "An agent-based approach to human migration movement”. 2016 Winter Simulation Conference (WSC). 3510-3520. https://doi.org/10.1109/WSC.2016.7822380

Luo, L., Zhou, S., Cai, W., Low, M. Y. H., Tian, F., Wang, Y., Xian, X., Chen, D. 2008. “Agent-based human behavior modeling for crowd simulation". Computer Animation and Virtual Worlds. 19(3-4), 271-281. https://doi.org/10.1002/cav.238. 


\section{Al-Khulaidy and Swartz}

Mcglade, J. 2014. "Simulation as Narrative: Contingency, Dialogics, and the Modeling Conundrum". Journal of Archaeological Method and Theory. 21(2).288-305.

Manning, P. 2005. Migration in World History. New York and London: Routledge.

Massey, D. S., \& Espinosa, K. E. 1997. "What's Driving Mexico-U.S. Migration? A Theoretical, Empirical, and Policy Analysis”. American Journal of Sociology. 102(4). 939-999. https://doi.org/10.1086/231037.

Migrant Social Networks: Vehicles for Migration, Integration, and Development. migrationpolicy.org. 2019. Retrieved April 23, 2019, from https://www.migrationpolicy.org/article/migrant-social-net works-vehicles-migration-integration-and-development.

Miller, J. H, Page, S. 2007. Complex Adaptive Systems. Princeton University Press.

Meyer, M., \& Isacson, A. 2019. "The "Wall” Before the Wall: Mexico's Crackdown on Migration at its Southern Border". https://www.wola.org/analysis/mexico-southern-border-report/

Moussaïd, M., Kämmer, J. E., Analytis, P. P., \& Neth, H. 2013. "Social Influence and the Collective Dynamics of Opinion Formation". PLOS ONE. 8(11). e78433. https://doi.org/10.1371/journal.pone.0078433

Ravenstein, E. G. 1885. "The Laws of Migration”. Journal of the Statistical Society of London. 48(2). 167235. https://doi.org/10.2307/2979181

Reynolds, Craig. 1987. Boids: Background and Update [Http://www.red3d.com/cwr/boids/].

Ryan, L. 2011. "Migrants' social networks and weak ties: accessing resources and constructing Relationships post-migration". The Sociological Review. 59(4). 707-724.

Schenk, T. A. 2014. 'Using stakeholders' narratives to build an agent-based simulation of a political Process". Simulation. 90(1), 85-102. https://doi.org/10.1177/0037549713514127

Simon, H. 1990. "A mechanism for social selection and successful altruism". Science. 250 (4988). 16658. doi:10.1126/science.2270480. PMID 2270480.

Simon, H. 1991. "Bounded Rationality and Organizational Learning". Organization Science. 2 (1). 125 134. doi:10.1287/orsc.2.1.125.

Simon, M. 2019. "Path Dependency and Adaptation: The Effects of Policy on Migration Systems". Journal of Artificial Societies and Social Simulation. 22 (2) 2. http://jasss.soc.sur rey.ac.uk/22/2/2.html>. doi: 10.18564/jasss.3970

Simon, M., Schwartz, C., Hudson, D., \& Johnson, S. D. 2018. "A data-driven computational model on the effects of immigration policies". Proceedings of the National Academy of Sciences. 115(34). E7914E7923. https://doi.org/10.1073/pnas.1800373115

Slater, M. D. 2007. "Reinforcing Spirals: The Mutual Influence of Media Selectivity and Media Effects and Their Impact on Individual Behavior and Social Identity". Communication Theory. 17(3). 281303. https://doi.org/10.1111/j.1468-2885.2007.00296.x

Stillwell, J, Bell, M., Ueffing, P., Daras, K., Charles-Edwards, E., Kupisezewski, M., \& Kupisezewska, D. 2016. "Internal migration around the world: comparing distance travelled and its frictional effect". SAGE Journals, Environment and Planning A: Economy and Space.

Stouffer, S. A. 1940. "Intervening Opportunities: A Theory Relating Mobility and Distance". American Sociological Review. 5(6).845. https://doi.org/10.2307/2084520

Suleimenova, D., Bell, D., \& Groen, D. 2017. "A generalized simulation development approach for predicting refugee destinations". Scientific Reports. 7(1). 13377. https://doi.org/10.1038/s41598-01713828-9

Tesfatsion, L. 2003. "Agent-based computational economics: Modeling economies as complex adaptive systems". Information Sciences. 149(4), 262-268.

Thöni, C., \& Gächter, S. 2015. "Peer effects and social preferences in voluntary cooperation: A theoretical and experimental analysis". Journal of Economic Psychology. 48(C). 72-88. https://doi.org/10.1016/j.joep.2015.03.001 


\section{Al-Khulaidy and Swartz}

UNHCR. Figures at a glance. United Nations High Commissioner for Refugees. 2017. Available at: http://www.unhcr.org/uk/figures-at-a-glance.html

U.S. Border Patrol. 2019. Southwest Border Sectors: Total Illegal Alien Apprehensions By Fiscal Year. U.S. Border Patrol. Retrieved from www.cbp.gov/sites/default/files/assets/documents/2019-Mar/bpsouthwestborder- sector-apps-fy1960-fy2018.pdf.

Wilensky, U. 2015. An introduction to agent-based modeling: modeling natural, social, and engineered complex systems with NetLogo. Cambridge, Massachusetts: MIT Press.

World Bank. 2018. TREND: World Bank. World Development Indicators. Statistical Datasets by Coquest Systems, Inc. Dataset-ID: 051-001-035. Retrieved from http://dx.doi.org/10.6068/DP14C4CC643DD22

\section{AUTHOR BIOGRAPHIES}

AMIRA AL-KHULAIDY is a Ph.D. student in Computational Social Sciences in the Department of Computational and Data Sciences at George Mason University. She holds a M.Ed. in Social Foundations of Education from the University of Virginia, and a B.A. in English with a concentration in Philosophy from Columbia University. Her research interests are in learning, education, and human behavior. Her email address is aalkhula@gmu.edu. GitHub: https://github.com/Aalk3/Migration-Spring-Sim-2020

MELANIE SWARTZ is a Ph.D. candidate in Computational Social Sciences (CSS) within the Department of Computational and Data Sciences at George Mason University. She holds a Master's degree in CSS and a B.S. in Geography. Her research interests are in understanding social-environmental interactions through modeling, simulation, network analysis, and data science. Her email is mswartz2@gmu.edu. GitHub: https://github.com/msgeocss/ABM_Migration_SpringSim2020 